\title{
Информационное освещение деятельности органов власти в Ярославской области как инструмент демобилизации граждан в общественно-политическом процессе
}

\author{
А. А. Фролов, Я. В. Барский \\ Ярославский государственный университет им. П.Г. Демидова \\ a.a.froloff@gmail.com, barski012@gmail.com
}

\section{Аннотация}

В статье авторами продемонстрированы результаты event-мониторинга информационного освещения деятельности органов власти и их представителей в Ярославской области за период с 1 декабря 2018 года по 31 декабря 2019 года. В результате проведения исследования удалось выявить специфику информационного освещения основных субъектов общественно-политического процесса и институтов власти в регионе. Методологической базой исследования стал ряд теорий, объясняющих прямые и косвенные факторы проявления гражданской активности. В работе тезисно описана теория относительной депривации, коллективной идентичности и коллективного действия. В результатах практико-ориентированного исследования представлена информация о количестве и долях информационных упоминаний, наиболее активных СМИ, участвовавших в освещении, а также новостных повестках, относящихся к тому или иному политическому актору. В статье приводится комплексный анализ собранного массива общественнополитической информации. Одним из выводов исследования является обобщенное описания механизма формирования позитивного образа власти путем публикации «событийной» новостной информации. Однако наиболее значимые для жителей города повестки, которые занимают значимую долю общего объема информационного освещения деятельности органов власти и их руководителей, имеют неоднозначную эмоциональную окраску.

Ключевые слова: event-мониторинг, гражданская активность, информационное освещение, органы власти

Библиографическая ссылка: Фролов А.А., Барский Я.В. Информационное освещение деятельности органов власти в Ярославской области как инструмент демобилизации граждан в общественно-политическом процессе // Государство и граждане в электронной среде. Выпуск 4 (Труды XXIII Международной объединенной научной конференции «Интернет и современное общество», IMS-2020, Санкт-Петербург, $17-20$ июня 2020 г. Сборник научных статей). - СПб: Университет ИТМО, 2020. С. 86-95. DOI: 10.17586/2541-979X-4-86-95

\section{1. Введение}

В российской политической практике органы власти являются неотъемлемыми субъектами общественно-политического процесса в силу имеющихся у них исполнительно-распорядительных и нормотворческих властных полномочий. Взаимодействие субъектов общественно-политического процесса может проходить в плоскостях аппаратной и публичной политики. Аппаратная политика, в силу анонимности или отсутствия выражающего ее субъекта, носит непубличный и вероятностный характер и у исследователя может возникнуть ряд трудностей с тем, чтобы подтвердить 
полученную информацию. Однако плоскость публичной политики имеет четко выраженных субъектов и среду проявления, что позволяет применять методы политического анализа для проведения практико-ориентированных политологических исследований. В статье представлен продолжающийся авторский event-мониторинг информационного освещения действий органов власти Ярославской области и их руководителей в публичном пространстве региона, формализированные результаты которого позволили применить метод case-study для качественного анализа политической действительности региона центральной России. Выбор методики проведения исследования объясняется авторами тем, что новостная общественно-политическая информация является ключевым фактором, способствующим формированию у жителей региона оценочного отношения к политической действительности, субъектам и институтам власти в Ярославской области. В свою очередь, оценочное отношение деятельности органов власти, опирающееся на новостную информацию из СМИ, способствует проявлению различных ситуативных форм активной или пассивной (латентной) поддержки или протеста против сложившегося положения вещей в общественной жизни. Более того, разработкой и распространением новостной информации занимаются средства массовой информации - другой ключевой субъект общественно-политического процесса. От специфики информационного освещения зависит качественное восприятие политической действительности жителями региона потребителями новостного контента. Также работа СМИ проходит в строгих границах российского правового поля, что позволяет считать информацию достоверной. Отметим, что в современных условиях развития электронных средств коммуникации, подавляющее большинство СМИ имеют корпоративные аккаунты в социальных сетях, контент в которых дублируется.

\section{2. Методологическая основа проведения исследования}

В теоретическую основу исследования вошел ряд концепций политической науки: теория коллективного действия, идентичности, а также - относительной депривации. При разработке научного материала авторами статьи был проанализирован опыт как «классиков» политической мысли в этих предметных областях, так и новейшие разработки западных ученых-политологов, занимающихся изучением выбранных в качестве методологической базы теорий. Теория относительной депривации имеет междисциплинарный характер и объясняет взаимосвязь между восприятием политической действительности и политическим поведением людей. Термин «депривация» понимается как состояние несоответствия человеческого представления о чем-либо с его фактическим состоянием. Ученые, стоявшие у истоков, пришли к выводу, что социально-экономические факторы имеют наибольшее влияние на картину политической действительности. При несоотносимых ожиданиях и действительности у человека может появиться ощущение дискомфорта или неудовольствия собственной жизнью, что формирует чувство социальной несправедливости, которое является базовым фактором для проявления протестной активности [3, p. 1223-1250]. Исследователей [4, p.125] интересовала гипотеза о взаимосвязи относительных материальных лишений с человеческим самоощущением низкого уровня жизни, уровня преступности и экономической депривации. В ходе изыскания ученые нашли и систематизировали множество открытых или скрытых психологических состояний, объединяющих понятием депривации.

Теория коллективной идентичности остается значимой научной проблемой в политологии и современных эмпирических исследованиях. Например, Мануэль Кастельс [1] понимал идентичность как процесс, при котором на основе приоритетных для человека культурных свойств появляется смысл, одинаково разделяемый разными людьми. Уильям Конноли [2, p. 278] понимал процесс формирования идентичности относительно осознанных различий. 
В теории коллективной идентичности можно выделить несколько основных подходов: первый определяет идентичность относительно общей структуры психологических систем человека. В этом случае идентичность понимается в качестве бессознательного внутриличностного процесса социализации индивида, понимая под этим внутреннюю согласованность. Представители второго подхода понимают идентичность как совокупность символических средств выражения идей, опосредующих отношение человека к социальным категориям - акцент смещен в большей степени на социологические аспекты. Между этими полярными мнениями сформировался и смешанный подход [8, p. 523], рассматривающий социальную идентичность как сложную когнитивную систему, которая складывается благодаря самоопределению нравственных, физических и интеллектуальных компонентов, а также социальной идентичности, определяющей принадлежность индивида к социальной группе. Понимание теории становится особенно интересным в ключе совокупности маркеров с высокой степенью идентичности, которые демонстрируют характер отношения людей к экономическим, общественным и политическим институтам. В таком аспекте коллективную идентичность можно определить как процесс взаимодействия и взаимовлияния человека и его институциональной среды обитания. Идентичность отражает язык, историю и политическую культуры. Теория также рассматривает механизмы вовлечения и удержания субъектов общественном пространстве.

Теория коллективного действия также стала важной частью методологической базы исследования. Смысловым ядром всей теории коллективных действий является определение «коллективного действия», которое сформулировал теоретик политической науки Мансур Олсон, понимавший его как процесс действий индивида в группе, направленных на получение общественного блага при незначительных издержках. Первые результаты исследования коллективных действий выявили следующую закономерность: чем ниже субъективное восприятия своей группы в социальной иерархии, тем больше вероятность проявления ими коллективных действий [6, с. 320-338]. Потенциал к проявлению коллективных действий формируется на основе ощущения группой диспропорции социального блага, которое появляется из осознания неравенства доступа к различным ресурсам [7, с. 319-331]. Опыт проведенных исследований в этой области позволяет говорить о ненависти и гневе как об основной силе, мотивирующей людей к участию в протестных мероприятиях [5, с. 602-616]. Движущей силой в этом случае можно считать уверенность людей в положительных для них результатах совместных коллективных действий.

Одним из наиболее авторитетных современных теоретиков является Мартин Ван Зомерен, который предложил двухфакторную модель коллективных действий. Основными факторами теории являлись групповые эмоции и субъективная вероятность успешности коллективных действий группы [9, с. 649-664]. В условиях осознания социальной несправедливости группой, её вероятное поведение может приобрести несколько векторов своего развития: поиск эмоциональной поддержки у членов группы относительно сложившейся ситуации и коллективная артикуляция оценочного суждения. В таком векторе деструктивные чувства, испытываемые членами группы, возрастают и обретают кумулятивный эффект. Второй вектор развития - оценка действий других членов группы и поиск удовлетворения потребности в инструментальной поддержке. При обнаружении индивидом схожести своих действий с действиями других членов группы, вероятность проявления коллективных протестных действий значительно увеличивается. Стоит отметить взаимодополняющий характер векторов развития событий. Таким образом, алгоритм проявления коллективного действия выглядит следующим образом: принятие решения индивидом о значимости для него несправедливого положения группы. Вторичная оценка значимости, прогнозирование последствий невыгодного положения группы и генерации эффективных механизмов для совладения со сложившейся ситуации. 


\section{3. Методика проведения исследования}

Возвращаясь к практической плоскости проведения исследования, стоит в нескольких словах рассказать о методике проведения изыскания: с целью выявления специфики информационного освещения деятельности органов власти и их руководителей в Ярославской области проводился сбор, анализ и последующая интерпретация общественно-политической информации путем корректного применения методов политического анализа - event-анализа и case-study. В созданной авторами кодировочной базе содержится более 21418 новостных сообщений, собранных за период времени с 1 декабря 2018 года по 31 декабря 2019 года. Источниками проведения исследования стал ресурс «Яндекс. Новости», где при помощи использования ключевых слов происходил поиск искомой новостной информации. Для определения предметных границ из общего информационного массива вычленялись те новости, которые содержали упоминание органов власти Ярославской области: муниципалитета города, мэрии, областной Думы и регионального правительства. Также был проведен сбор и анализ новостей с упоминанием руководителей органов власти: председателя муниципалитета города Ярославля Артура Евгеньевича Ефремова, мэра города Ярославля Владимира Михайловича Волкова, председателя Ярославской областной Думы Алексея Дмитриевича Константинова и председателя регионального правительства Дмитрия Александровича Степаненко. Формализация новостного материала происходила путем присвоения ему порядкового номера, даты опубликования новости, формализованного указания новостного агентства, сохранения гиперссылки на первоисточник для проведения качественного анализа, а также указания предметной области новостной статьи по заранее утвержденной системе классификаторов и указания относящихся к новости субъектов. Для проведения качественного анализа был применен метод case-study, с помощью которого удалось выявить сущностные характеристики исследуемых кейсов, определить границы общественно-политического процесса и выявить активных политических субъектов региона.

\section{4. Специфика информационного освещения деятельности органов власти и их руководителей в Ярославской области наиболее активными СМИ}

В результате проведения event-мониторинга удалось выявить специфику количественного информационного освещения органов власти и их руководителей в Ярославской области (Рисунки 1-3).

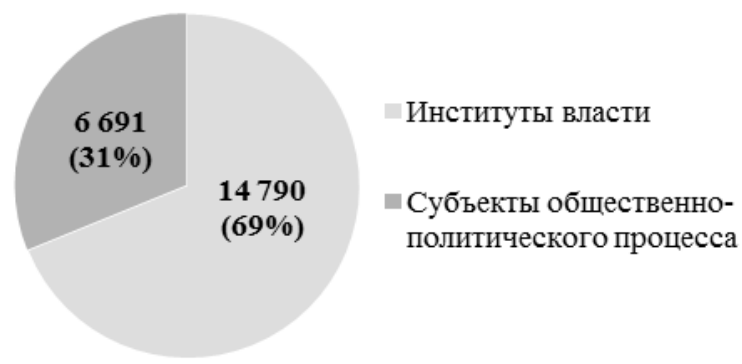

Рис. 1. Количественные показатели информационного освещения деятельности органов власти и их руководителей в Ярославской области 


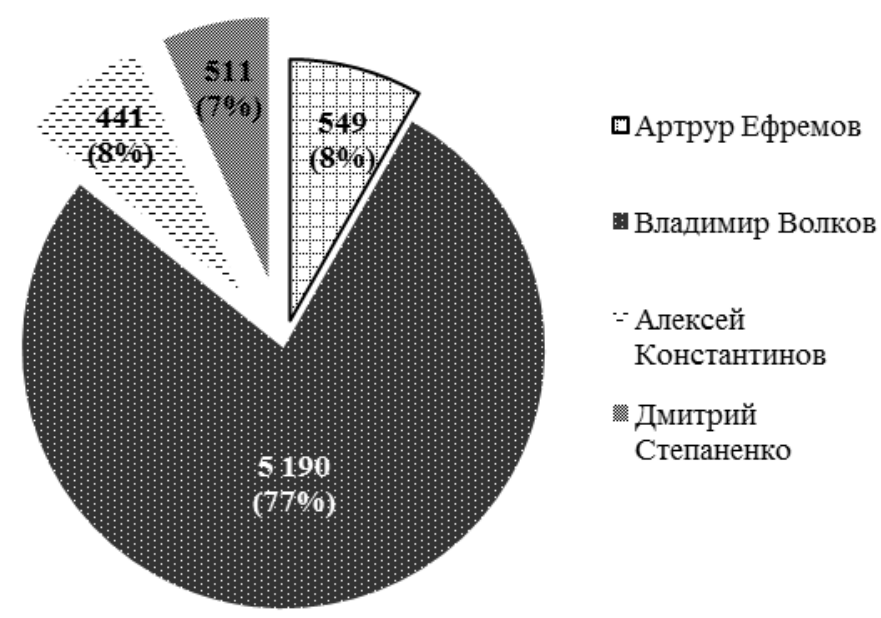

Рис. 2. Количественные показатели информационного освещения руководителей органов власти в Ярославской области

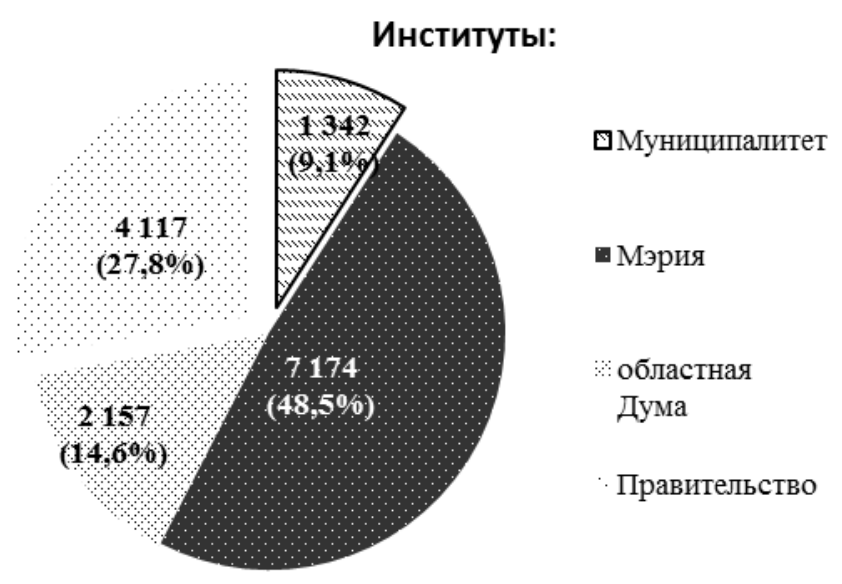

Рис. 3. Количественные показатели информационного освещения деятельности органов власти в Ярославской области

Значительная доля зафиксированных новостных сообщений (68,85\%) содержала в себе упоминание институтов власти, что объясняется более широким перечнем стоящих перед ними задач. Большее внимание СМИ (76,3\%) привлекла работа исполнительнораспорядительной власти, а не законодательной или представительной, что связано с большим количеством общественно значимых предметов для освещения, а также большим количеством властных полномочий, проявляющих себя в городской жизни. Несколько иначе выглядит информационное освещение руководителей органов власти: здесь в большей мере прослеживается непропорционально большое $(77 \%)$ информационное освещение деятельности мэра города, избранного представительным органом 5 декабря 2018 года. Также в ходе исследования удалось вывести количественный график и объяснить динамику информационного освещения (Рисунки 4-5). 

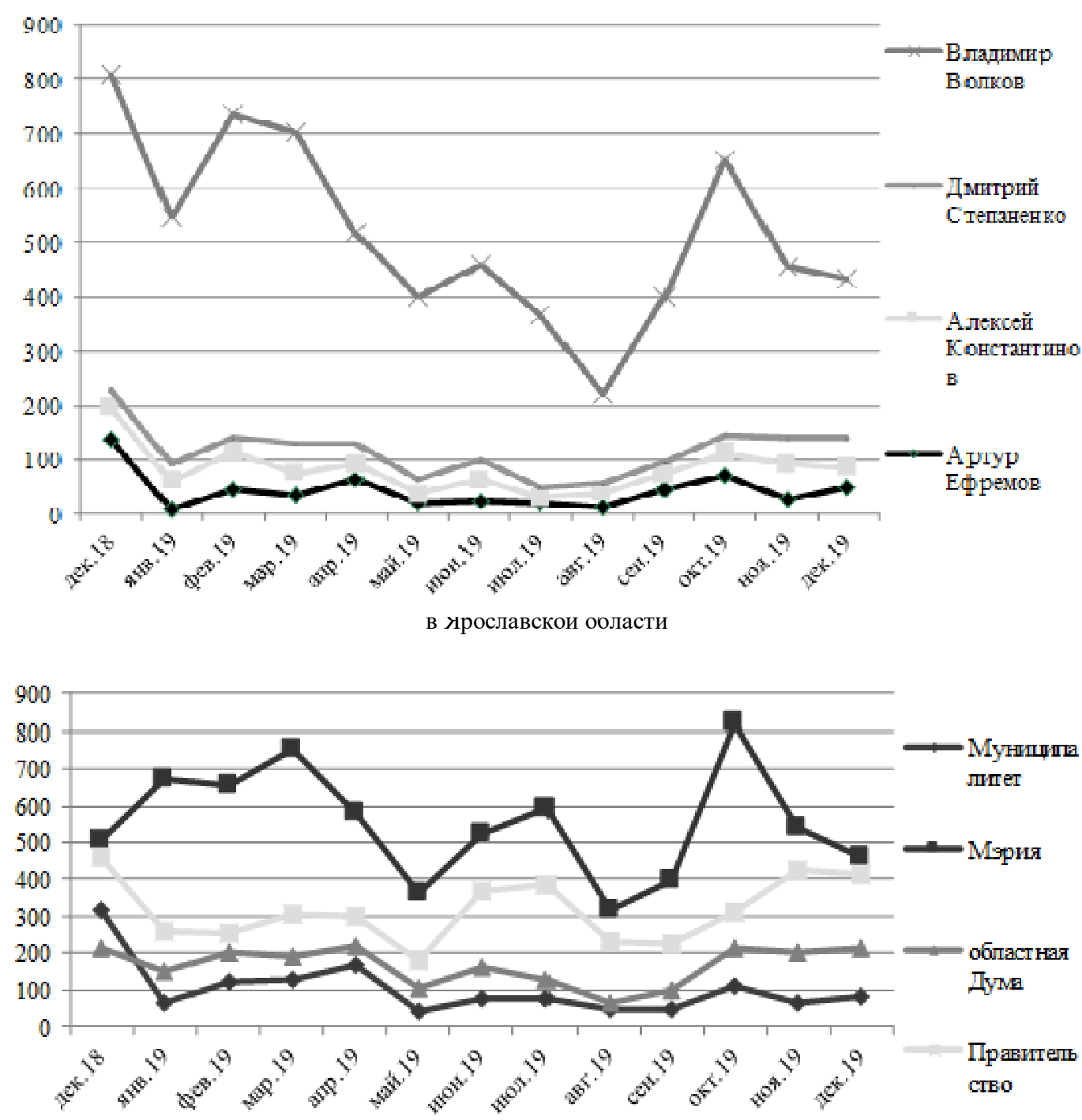

Рис. 5. Динамика информационного освещения деятельности органов власти в Ярославской области

На представленных графиках отчетливо видна сезонность информационного освещения как институтов власти, так и субъектов политического процесса. Упоминания о деятельности представителей органов власти содержали 6691 новостных сообщений (31,24\% от общего объема сообщений). Из них 5190 новостных сообщений $(77,57 \%)$ касалось деятельности мэра города Ярославля, в 549 сообщениях $(8,21 \%)$ упоминался председатель муниципалитета города Ярославля, в 511 сообщениях (7,64\%) председатель Ярославской областной Думы и в 441 сообщении $(6,59 \%)$ - председатель регионального правительства. Наиболее высокие показатели информационного освещения всех субъектов общественно-политического процесса зафиксированы в конце 2018 года, 
что связано с процедурой избрания и вступления в права мэра города Владимира Михайловича Волкова. При общей тенденции к незначительному снижению интенсивности новостных публикаций в начале 2019 года, в это время можно увидеть достаточно резкие подъемы, связанные с привлечением внимания СМИ к вопросам качества уборки города, которые сопровождались такими ситуациями как несчастные случаи, пробки на дорогах, затруднение при использовании общественного транспорта. С января по март 2019 года в информационном освещении институтов власти (главным образом мэрии города Ярославля) также наблюдаются всплески информационной активности, связанные с кадровыми решениями вновь избранного главы города в отношении директоров предприятий муниципального сектора экономики, заместителей мэра и руководителей структурных подразделений исполнительно-распорядительной власти города.

Увеличение интенсивности освещения осенью 2019 года связаны с затянувшимся началом отопительного сезона, исполнения нацпроекта «Безопасные и качественные автомобильные дороги» и региональной программы по благоустройству «Решаем вместе!», а также выполнения работ по ямочному ремонту дорог. Однако летний период дорожных работ и благоустройства города остался в меньшем фокусе внимания СМИ, что говорит о низкой степени заинтересованности власти в освещении «хозяйственной» повестки, ставшей предметом для общественного обсуждения в зимний период.

Исследование позволило выявить СМИ, наиболее активно участвовавшие в информационном освещении субъектов публичного пространства. В информационном освещении за указанный период участвовало 536 СМИ. Также были выделены и систематизированы информационные поводы, о которых писали наиболее активные СМИ (Рисунок 6).

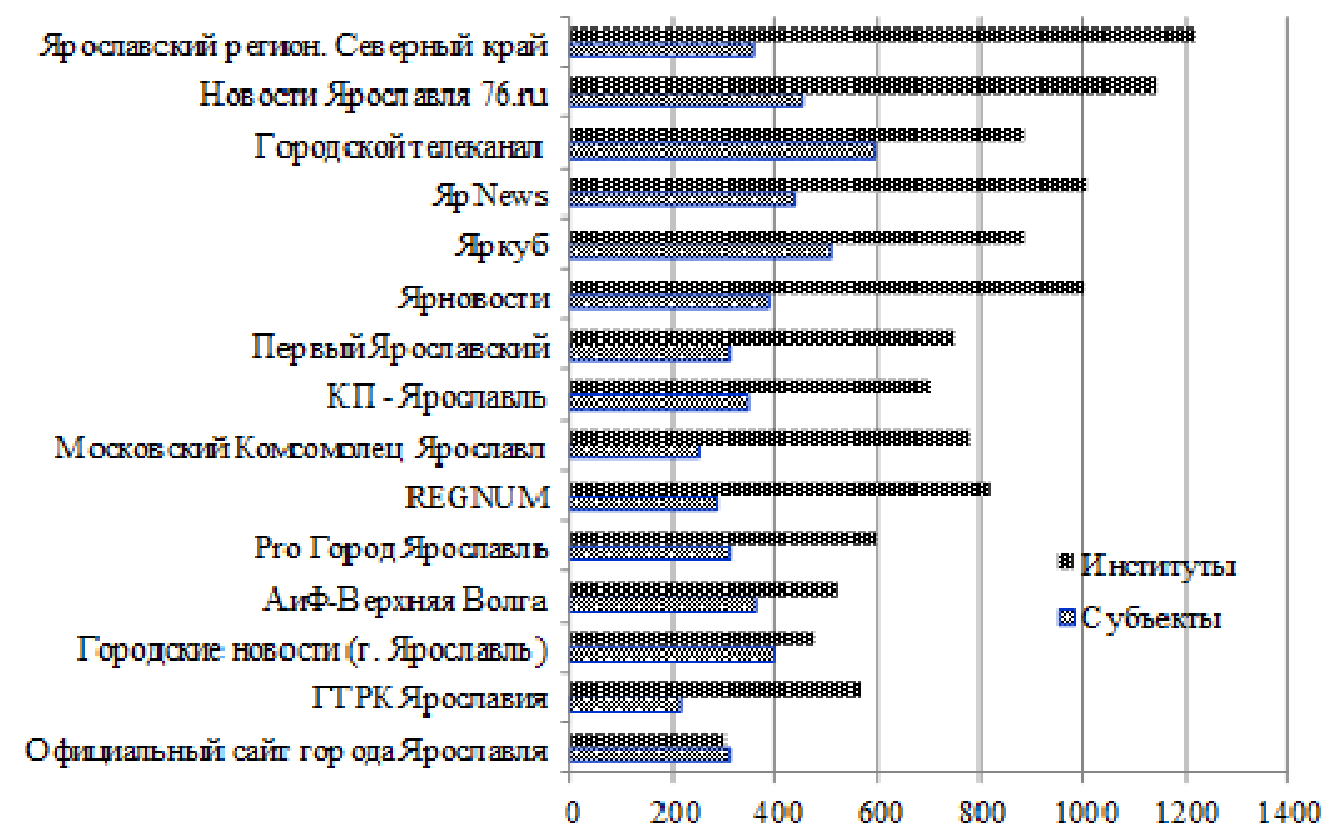

Рис. 6. Количественные показатели информационного освещения деятельности органов власти и их руководителей в Ярославской области наиболее активными СМИ 
Говоря о предметах информационного освещения, стоит отметить значимую долю различных городских и региональных событий - 2614 сообщений $(12,2 \%)$, под которыми понимаются государственные праздники, памятные дни, открытия различных объектов форумы, конференции и соревнования, а также юбилеи муниципальных и государственных учреждений. В большей части зафиксированных «событий» упоминается региональное правительство в качестве соорганизатора как общегородских мероприятий, так и региональных. Дорожная отрасль: исполнение национального проекта «Безопасные и качественные дороги», проведение ямочного ремонта и нанесение дорожной разметки было освещено в 1869 сообщениях (8,73\%). При этом подавляющее количество новостей было посвящено дорожному строительству в городе Ярославле и имело негативный эмоциональный окрас. Более 1500 новостных сообщений СМИ было посвящено жилищнокоммунальному хозяйству, более трети сообщений (530) освещало процесс зимней уборки в Ярославле. Изменения внутри сферы пассажирских перевозок были освещены в 1055 новостных сообщениях. Сфера благоустройства, главным источником финансирования которой является губернаторский проект «Решаем вместе!», была освещена в 946 сообщениях. Кадровые решения мэра города Владимира Михайловича Волкова были освещены в 789 новостных сообщениях, при этом большая часть из них носила ярко выраженный негативный эмоциональный окрас.

\section{5. Выводы}

Результаты проведения исследования говорят о значительной доле «событийного» информационного освещения деятельности органов власти и их руководителей в Ярославской области. Отметим, что подобные мероприятия, как правило, хорошо организованы, носят торжественный характер и имеют положительный эмоциональный окрас. Проанализированные информационные сообщения говорят о том, что по средствам публикации положительно-окрашенного новостного контента органы власти и их руководители стараются создать позитивную информационную повестку в Ярославле и области, чтобы тем самым снизить негативное воздействие феномена относительной депривации на жителей региона и уменьшить их протестный потенциал. Однако среди многочисленных упоминаний «событий» присутствует многочисленная категория новостей, отнесенная к разделу «общество» (20,63\%). Эмоциональный окрас этой категории нельзя назвать исключительно позитивным, так как некоторые поводы, такие как объединение «Первого русского театра имени Волкова» или скандал со срывом конкурса на выполнение ямочного ремонта дорог, имеют ярко выраженный негативный эмоциональный окрас.

Отраслевой анализ повесток информационного освещения говорит, что большим спросом у жителей (следовательно и предложением от СМИ) пользуются злободневные хозяйственные темы: «дороги» - качество и ремонт дорог $(11,3 \%)$; «ЖКХ» - качество уборки города, выполнение капитального ремонта жилых домов $(9,6 \%)$; «Благоустройство» - выполнение программы по благоустройству городской среды «Решаем вместе!», ремонт дворов и дворовых проездов (5,5\%). При этом если отрасль благоустройства еще имеет достаточное количество положительных публикаций, так как главным механизмом выполнения работ является специальная программа, то в дорожной и жилищно-коммунальной отрасли общественный запрос формировался на основе имеющихся проблем, требующих безотлагательного решения. Сфера общественного транспорта $(6,1 \%)$ также является хорошо освещенной темой, однако наряду с высокой активностью СМИ, публиковавших информацию о положительных изменениях, в повестку вошли и негативно окрашенные процессы - продажа здания троллейбусного депо и повышение стоимости проезда в городе Ярославле, перераспределение объема перевозок между хозяйствующими субъектами и другие информационные поводы. Сфера строительства $(5,1 \%)$ была представлена выполнением нацпроектом «Образование» и 
«Демография», по которым в городе строятся социальные объекты, а также выполнением программы по расселению граждан из аварийного жилого фонда, что имеет ярко выраженную позитивную эмоциональную окраску. Практически в той же доле $(4,9 \%)$ была освещена тема кадровой политики, которая выражалась в новостных публикациях с оценочным содержанием и имела ярко выраженную негативную эмоциональную окраску.

Таким образом, можно отметить, что среди указанных отраслей и тем, которые освещались на протяжении прошедшего года, наиболее многочисленные и значимые для населения темы имели негативный эмоциональный окрас, что выступает фактором мобилизации жителей к проявлению протестной активности. Но вместе с этим закономерности в информационном освещении руководителей и органов власти в Ярославской области показывают стремление снизить влияние феномена относительной депривации и демобилизировать жителей к проявлению протестной активности.

Статья подготовлена в рамках исследования, финансируемого за счет гранта Президента Российской Федерации для государственной поддержки молодых российских ученых МД-855.2020.6 «Мобилизация и демобилизация в современных практиках протестной активности»

\title{
Литература
}

[1] Castells M. The power of identity // Cambridge: Blackwell Publishers, 1997. 461 p.

[2] Connolly W. Identity. Difference: Democratic negotiations of political paradox. Ithaca: Cornell University Press, 1991. 278 p.

[3] Gunnar B., Thorlindsson T., Sigfusdottir I.D. Relative Deprivation and Adolescent in Iceland: A Multilevel Test // Social Forces. 2009. Vol. 87(3). P. 1223-1250.

[4] Jarjoura R., Triplett R. The Effects of Social Area Characteristics on the Relationship Between Social Class and Delinquency // Journal of Criminal Justice. 1997. Vol. 25(2). P. 125.

[5] Mackie D. Inter-group Emotions: Explaining Offensive Action Tendencies in an Intergroup Context // Journal of Personality and Social Psychology. 2000. Vol. 79(4). P. 602-616.

[6] Postmes T., Branscombe N., Spears R., Young H. Comparative Processes in Personal and Group Judgments: Resolving the Discrepancy // Journal of Personality and Social Psychology. 1999. Vol. 76(2). P. 320-338.

[7] Simon B., Klandermans B. Politicized Collective Identity. A Social Psychological Analysis // American Psychologist. 2001. Vol. 56(4). P. 319-331.

[8] Tajfel H. Social identity and intergroup relations. Cambridge: Cambridge University Press, $2010.523 \mathrm{p}$.

[9] Van Zomeren M., Spears R., Fischer A., Leach C. Put Your Money Where Your Mouth Is! Explaining Collective Action. Tendencies Through Group-Based Anger and Group Efficacy // Journal of Personality and Social Psychology. 2004. Vol. 87(5). P. 649-664.

\section{Information Coverage of the Activities of Government in the Yaroslavl Region as a Tool for the Demobilization of Citizens in the Sociopolitical Process}

\author{
A. Frolov, Y. Barskiy
}

\section{P. G. Demidov Yaroslavl State University}

In the paper, the authors demonstrate the results of event monitoring of information coverage of the activities of authorities and their representatives in the Yaroslavl region for the period from December 1, 2018 to December 31, 2019. As a result of the research, it was possible to identify the specifics of information coverage of the main subjects of the socio-political process and 
government institutions in the region. The methodological basis of the research is a number of theories that explain direct and indirect factors of civil activity. The paper describes the theory of relative deprivation, collective identity and collective action. The results of the practice-oriented research provide information about the number and proportion of information mentions, the most active media that participated in coverage, as well as news agendas related to a particular political actor. The article provides a comprehensive analysis of the collected mass of sociopolitical information. One of the conclusions of the study is a generalized description of the mechanism of forming a positive image of power by publishing "event" news information. However, the most important issues for residents of the city, which occupy a significant share of the total volume of information coverage of the activities of authorities and their leaders, have an ambiguous emotional color.

Keywords: event-monitoring, civic activity, information coverage, government

Reference for citation: Frolov A., Barskiy Y. Information Coverage of the Activities of Government in the Yaroslavl Region as a Tool for the Demobilization of Citizens in the Sociopolitical Process // The State and Citizens in the Electronic Environment. Vol. 4 (Proceedings of the XXIII International Joint Scientific Conference "Internet and Modern Society», IMS-2020, St. Petersburg, June 17-20, 2020). - St. Petersburg: ITMO University, 2020. P. 86-95. DOI: 10.17586/2541-979X-4-86-95

\section{Reference}

[1] Castells M. The power of identity // Cambridge: Blackwell Publishers, 1997. $461 \mathrm{p}$.

[2] Connolly W. Identity. Difference: Democratic negotiations of political paradox. Ithaca: Cornell University Press, 1991. 278 p.

[3] Gunnar B., Thorlindsson T., Sigfusdottir I.D. Relative Deprivation and Adolescent in Iceland: A Multilevel Test // Social Forces. 2009. Vol. 87(3). P. 1223-1250.

[4] Jarjoura R., Triplett R. The Effects of Social Area Characteristics on the Relationship Between Social Class and Delinquency // Journal of Criminal Justice. 1997. Vol. 25(2). P. 125.

[5] Mackie D. Inter-group Emotions: Explaining Offensive Action Tendencies in an Intergroup Context // Journal of Personality and Social Psychology. 2000. Vol. 79(4). P. 602-616.

[6] Postmes T., Branscombe N., Spears R., Young H. Comparative Processes in Personal and Group Judgments: Resolving the Discrepancy // Journal of Personality and Social Psychology. 1999. Vol. 76(2). P. 320-338.

[7] Simon B., Klandermans B. Politicized Collective Identity. A Social Psychological Analysis // American Psychologist. 2001. Vol. 56(4). P. 319-331.

[8] Tajfel H. Social identity and intergroup relations. Cambridge: Cambridge University Press, 2010. $-523 \mathrm{p}$.

[9] Van Zomeren M., Spears R., Fischer A., Leach C. Put Your Money Where Your Mouth Is! Explaining Collective Action. Tendencies Through Group-Based Anger and Group Efficacy // Journal of Personality and Social Psychology. 2004. Vol. 87(5). P. 649-664. 